\title{
Ácidos graxos da gordura de cobertura do contrafilé de bovinos Nelore e Canchim terminados em confinamento e alimentados com diferentes níveis de concentrado nas dietas
}

\author{
Fatty acids composition of loin backfat of Nellore and Canchim \\ bovines finished at feedlot and fed with differents levels of \\ concentrate in diets
}

\begin{abstract}
Alexandre Rodrigo Mendes Fernandes ${ }^{1 *}$; Alexandre Amstalden Moraes Sampaio ${ }^{2}$; Emanuel Almeida de Oliveira ${ }^{3}$; Thiago Martins Pivaro ${ }^{4}$; Wignez Henrique ; Bruna Laurindo Rosa ${ }^{4}$; José Carlos da Silveira Osórioํㅜㄹ Maria Teresa Moreira Osório ${ }^{1}$
\end{abstract}

\section{Resumo}

\begin{abstract}
O objetivo foi avaliar a composição em ácidos graxos da gordura de cobertura do contrafilé (músculo Longissimus) de tourinhos das raças Nelore e Canchim. Os animais foram terminados em confinamento e alimentados com dietas contendo cana-de-açúcar e duas proporções de concentrado (40 e 60\% na matéria seca). Os concentrados foram compostos por grãos de girassol, milho, farelo de soja, levedura seca de cana-de-açúcar, uréia e núcleo mineral. O delineamento experimental foi o inteiramente ao acaso, em esquema fatorial 2x2 (grupo genético x nível de concentrado), sendo os resultados submetidos à análise de variância e as médias comparadas pelo teste de Tukey a $5 \%$ de probabilidade, quando a interação foi significativa. A gordura de cobertura dos animais Nelore apresentou maior concentração de ácido linoléico conjugado do que a dos animais Canchim ( 0,86 e $0,59 \%$, respectivamente). Por outro lado, a gordura de cobertura dos animais Canchim apresentou maior concentração de ácido esteárico $(17,07 \%)$, linoléico $(2,40 \%)$ e ácidos graxos polinsaturados do que a dos animais Nelore, que mostraram valores de 13,47 e 1,44\%, respectivamente. A gordura de cobertura do contrafilé dos animais Canchim e Nelore apresenta quantidades significativas de ácidos graxos benéficos à saúde humana. Teores de 40 e $60 \%$ de concentrado na dieta não alteram a composição em ácidos graxos na gordura de cobertura.

Palavras-chave: Ácidos graxos polinsaturados, ácido linoléico conjugado, cana-de-açúcar, grãos de girassol
\end{abstract}

\footnotetext{
Abstract

The objective was to evaluate fatty acids composition of the back fat in loin meat (Longissimus muscle) from Nellore and Canchim young bulls. The animals were finished at feedlot and received sugar cane diets with two concentrate levels ( 40 and $60 \%$ of dry matter). The concentrates were formulated with sunflower grains, corn, soybean meal, dry sugar cane yeast, urea and mineral mixture. The experimental design was a completely randomized design with a $2 \times 2$ factorial arrangement (genetic group $\mathrm{x}$ concentrate level), and the results were submitted to the variance analysis and means compared by

Profs. da Universidade Federal da Grande Dourados, UFGD, Dourados, MS. E-mail: alexandrefernandes@ufgd.edu.br; jc.s.osorio@hotmail.com; m.tm.osorio@hotmail.com

2 Prof. da Universidade Estadual Paulista, UNESP, Jaboticabal, SP. E-mail: sampaio@fcav.unesp.br

3 Pesquisador da UNESP, Jaboticabal, SP. E-mail: moroto.oliveira@hotmail.com

4 Discentes da UNESP, Jaboticabal, SP. E-mail: thiagopivaro@hotmail.com; brunaarosa@hotmail.com

5 Pesquisador da Agência Paulista de Tecnologia do Agronegócio, São José do Rio Preto, SP. E-mail: wignez@terra.com.br Autor para correspondência
} 
Tukey test at 5\% probability, when the interaction was significant. The loin backfat of Nellore bulls had higher concentration of conjugated linoleic acids than Canchim bulls ( 0.86 and $0.59 \%$, respectively). On the other hand, the loin back fat of Canchim bulls had higher concentrations of estearic $(17.07 \%)$ and linoleic acids $(2.40 \%)$ and polyunsaturated fatty acids than Nellore bulls, that showed values of 13.47 and $1.44 \%$, respectively. The Nellore and Canchim loin back fat presents significant amounts of beneficial fatty acids to human health. Levels of 40 and $60 \%$ of concentrate in the diet did not alter the fatty acids composition of loin backfat.

Key words: Conjugated linoleic acid, polyunsaturated fatty acids, sugar cane, sunflower grains

\section{Introdução}

Nos últimos anos a carne bovina vem sendo associada ao aumento do colesterol, obesidade, à incidência de distúrbios metabólicos e doenças cardiovasculares (BIESALSKI, 2005). No Brasil, as doenças do coração são as que mais causam mortes, sendo responsáveis por aproximadamente $25 \%$ do total de óbitos. Níveis plasmáticos de colesterol, principalmente aquele associado às lipoproteínas de baixa densidade, sua fração mais aterogênica, constituem importantes fatores na predição do risco de doença arterial coronariana (VACANTI et al., 2005). Porém, conforme descrito por Taubes (2001), aproximadamente $50 \%$ dos infartos ocorrem em pessoas com níveis normais de colesterol, demonstrando que o fato do indivíduo ingerir menor quantidade de gordura animal não diminui a probabilidade de desenvolver doenças cardiovasculares. De acordo com o mesmo pesquisador, a convicção de que gordura na dieta pode até mesmo causar a morte do indivíduo, é um exemplo de como os meios de comunicação podem manipular a população, sobressaindo-se em relação à ciência.

Em função dessa nova exigência do consumidor, que busca produtos alimentícios mais saudáveis, a pesquisa zootécnica vem evoluindo no sentido de produzir carne bovina com melhor composição em ácidos graxos, ressaltando a contribuição desse nobre alimento como parte de uma dieta saudável e como fonte de nutrientes essenciais para o adequado funcionamento do organismo. Nesse contexto, Mir et al. (2003), relataram que um dos fatores que mais afetam a composição dos lipídeos da carcaça, seja na gordura de cobertura ou nos depósitos intramusculares, é a alimentação dos animais. Outro fator determinante é a raça dos animais, pois esta característica está relacionada com a taxa de deposição de gordura e, aparentemente, a quantidade de gordura também afeta o perfil de ácidos graxos. Assim, bovinos Nelore e Canchim podem ser utilizados como modelos para avaliar o efeito do grau de terminação da carcaça na composição lipídica dos depósitos subcutâneos. Essas raças apresentam baixo nível de gordura intramuscular, porém, com relação à gordura de cobertura, apresentam diferenças no processo de acabamento.

O objetivo deste trabalho foi avaliar a composição deácidos graxos da gordura de cobertura do contrafilé de bovinos Nelore e Canchim, alimentados com dietas a base de cana-de-açúcar e duas proporções de concentrado, contendo grãos de girassol como fonte de ácidos graxos polinsaturados.

\section{Material e Métodos}

A fase de terminação dos animais foi desenvolvida no módulo de confinamento do Setor de Bovinocultura de Corte da Faculdade de Ciências Agrárias e Veterinárias/Unesp, Jaboticabal, SP. Foram utilizados 30 tourinhos, sendo 15 da raça Nelore com $330 \pm 21 \mathrm{~kg}$ e 18 meses de idade e 15 da raça Canchim com $300 \pm 24 \mathrm{~kg}$ e 15 meses de idade. A defasagem de peso corporal e idade foi proposital e esteve relacionada à taxa de desenvolvimento dos animais, objetivando o abate conjunto. As dietas experimentais contendo 40 e $60 \%$ de concentrado na matéria seca total foram formuladas visando o ganho de peso máximo de acordo com o sistema 
Cornell Net Carbohydrate and Protein System (FOX et al., 1992).

As composições percentuais (com base na matéria seca) e nutricionais, bem como a composição em ácidos graxos das dietas experimentais são apresentadas na Tabela 1. A variedade de cana-de-açúcar utilizada foi a SP 80-
1816, que apresenta boa quantidade de sacarose na época de corte (maio a outubro) e não é susceptível a tombamento, facilitando assim a mecanização do corte. Os ingredientes utilizados para compor os concentrados foram triturados em moinho provido de peneira com crivos de $2 \mathrm{~mm}$, e misturados em misturador horizontal por 5 minutos.

Tabela 1. Composição percentual (\%MS), características nutricionais e perfil de ácidos graxos das dietas.

\begin{tabular}{|c|c|c|c|}
\hline \multirow[b]{2}{*}{ Volumoso } & \multicolumn{3}{|c|}{ Composição bromatológica } \\
\hline & MS(\%) & PB $(\% \mathrm{MS})$ & $\mathrm{FDN}(\% \mathrm{MS})$ \\
\hline Cana-de-açúcar (Var. SP 80-1816) & 39,28 & 3,20 & 52,70 \\
\hline & \multicolumn{3}{|c|}{ Nível de concentrado na dieta ${ }^{1}$} \\
\hline Ingredientes & 40 & & 60 \\
\hline Cana-de-açúcar & 60,00 & & 40,00 \\
\hline Grãos de girassol & 9,10 & & 10,00 \\
\hline Farelo de soja & 7,50 & & 7,00 \\
\hline Milho grão & 17,50 & & 28,00 \\
\hline Levedura seca de cana-de-açúcar & 4,40 & & 13,80 \\
\hline Núcleo mineral & 0,30 & & 0,50 \\
\hline Uréia & 1,00 & & 0,40 \\
\hline Bicarbonato de sódio & 0,20 & & 0,30 \\
\hline \multicolumn{4}{|c|}{ Composição nutricional $^{2}$} \\
\hline MS (\%) & 38,59 & & 47,54 \\
\hline PB (\% MS) & 12,82 & & 14,95 \\
\hline NDT (\% MS) & 69,00 & & 74,15 \\
\hline $\mathrm{EE}(\% \mathrm{MS})$ & 3,50 & & 4,60 \\
\hline EM (MJ/kg MS) & 10,74 & & 11,54 \\
\hline Ganho estimado (kg/animal/dia) & 1,0 & & 1,3 \\
\hline \multicolumn{4}{|c|}{ Perfil de ácidos graxos (\% dos ácidos graxos totais) } \\
\hline 14:0 Mirístico & 0,30 & & 0,24 \\
\hline 16:0 Palmítico & 11,22 & & 10,21 \\
\hline 16:1 c9 Palmitoléico & 0,27 & & 0,55 \\
\hline 18:0 Esteárico & 4,52 & & 4,33 \\
\hline 18:1 c9 Oléico & 23,97 & & 25,26 \\
\hline 18:2 c9, c12 Linoléico & 54,28 & & 52,35 \\
\hline 18:3 c9, c12, c15 Linolênico & 1,05 & & 0,32 \\
\hline 20:0 Araquídico & 0,36 & & 0,39 \\
\hline
\end{tabular}

${ }^{1} 40$ - Dieta composta com cana-de-açúcar e 40\% de concentrado; 60 - Dieta composta com cana-de-açúcar e $60 \%$ de concentrado. ${ }^{2}$ MS - Matéria seca; PB - proteína bruta; NDT nutrientes digestíveis totais; EE - extrato etéreo; EM - energia metabolizável.

Fonte: Elaboração dos autores.

Ao final de 105 dias de confinamento, os animais foram enviados a um frigorífico comercial, onde após 24 horas do embarque, seguiram os procedimentos rotineiros de abate. Os animais Nelore e Canchim apresentaram pesos médios de carcaça quente de 262,06 e $246,78 \mathrm{~kg}$, com média de cobertura de gordura de 5,5 e 3,2 mm, respectivamente. Quando observado o nível de concentrado, foram obtidos 
pesos de carcaça quente de 244,70 e $265,39 \mathrm{~kg}$, e cobertura de gordura de 4,0 e 4,9 mm, para as dietas com 40 e $60 \%$ de concentrado, respectivamente (OLIVEIRA et al., 2009).

Todos os procedimentos experimentais, do confinamento ao abate, foram submetidos à apreciação da Comissão de Ética e Bem Estar Animal (CEBEA) da FCAV/Unesp e receberam aprovação.

Após 24 horas de resfriamento das carcaças, foi retirada de cada meia-carcaça esquerda uma amostra do músculo Longissimus, compreendida entre a $11^{\mathrm{a}}$ e $13^{\mathrm{a}}$ costelas. De cada seção do músculo, foram retiradas amostras da gordura de cobertura para posterior extração da fração lipídica, segundo metodologia desenvolvida por Bligh e Dyer (1959). Para a transesterificação dos triglicerídeos, aproximadamente $50 \mathrm{mg}$ da matéria lipídica extraída foi transferida para tubos falcon de $15 \mathrm{~mL}$, em que foram adicionados $2 \mathrm{~mL}$ de n-heptano. A mistura foi agitada até a completa dissolução da matéria graxa e, então, $2 \mathrm{~mL}$ de $\mathrm{KOH}$ $2 \mathrm{~mol} / \mathrm{L}$ em metanol foram adicionados, sendo essa mistura agitada por aproximadamente 5 minutos. Após a separação das fases, $1 \mathrm{~mL}$ da fase superior (heptano e ésteres metílicos de ácidos graxos) foram transferidos para frascos eppendorf de 1,5 mL. Os frascos foram hermeticamente fechados, protegidos da luz e armazenados em congelador a $-18^{\circ} \mathrm{C}$, para posterior análise cromatográfica (FERNANDES et al., 2009b).

A composição em ácidos graxos foi determinada por cromatografia gasosa de alta resolução, utilizando-se cromatógrafo a gás, equipado com coluna capilar SP-2560 de $100 \mathrm{~m}$ de comprimento e diâmetro de $0,25 \mathrm{~mm}$, acoplado a um detector de ionização de chama. A temperatura foi programada para iniciar em $130^{\circ} \mathrm{C}$, permanecendo assim por 1 minuto, sendo então elevada a $170^{\circ} \mathrm{C}$ à taxa de $6,5^{\circ} \mathrm{C} /$ minuto. Posteriormente, outra elevação de temperatura de 170 a $215^{\circ} \mathrm{C}$ foi realizada a $2,75^{\circ}$ $\mathrm{C} /$ minuto, permanecendo nesta temperatura por
12 minutos. Finalmente, uma última elevação foi realizada de 215 para $230^{\circ} \mathrm{C}$ a uma taxa de $40^{\circ}$ $\mathrm{C} /$ minuto. As temperaturas do injetor e detector foram de $270^{\circ}$ e $280^{\circ} \mathrm{C}$, respectivamente, sendo as amostras de $0,3 \mu \mathrm{L}$, injetadas em modo "split", utilizando-se hidrogênio como gás carreador. A identificação dos ésteres metílicos de ácidos graxos foi realizada por comparação com os tempos de retenção e as concentrações dos ácidos graxos de padrões autênticos, metilados e eluídos nas mesmas condições (FERNANDES et al., 2009b).

Foram calculados os índices de atividade das enzimas $\Delta^{9}$-Dessaturase $\mathrm{C} 16$ e $\mathrm{C} 18$, responsáveis pela conversão dos ácidos graxos palmítico (C16:0) e esteárico (C18:0) em seus correspondentes monoinsaturados, com ligação dupla no carbono 9 (MALAU-ADULI et al., 1997).

Os resultados foram submetidos à análise de variância, em que o modelo estatístico incluiu os efeitos de grupo genético (Nelore e Canchim), teor de concentrado na dieta (40 e 60\%) e suas interações. As médias foram comparadas pelo teste de Tukey, considerando o nível de significância de 5\% de probabilidade, quando o teste $\mathrm{F}$ foi significativo para a interação de fatores (SAMPAIO, 2002).

\section{Resultados e Discusão}

Não houve interação significativa $(\mathrm{P}>0,05)$ entre grupo genético e nível de concentrado nas dietas em todas as variáveis analisadas. A Tabela 2 apresenta os resultados da análise de composição em ácidos graxos saturados da gordura de cobertura do contrafilé, considerando os fatores raça e nível de concentrado, separadamente.

Os animais da raça Nelore apresentaram $(\mathrm{P}<0,05)$ gordura de cobertura do contrafilé com maiores proporções dos ácidos graxos mirístico (C14:0) em relação aos da raça Canchim, que mostraram valores mais elevados para o ácido graxo esteárico (C18:0). Fernandes et al. (2009b) avaliaram as concentrações dos principais ácidos graxos na carne do contrafilé 
de bovinos Nelore e Canchim e não observaram diferenças entre as concentrações do ácido mirístico, porém relataram, assim como no presente trabalho, maior concentração de ácido esteárico na carne dos animais Canchim (16,21 x 14,32\%). Esse resultado pode estar associado com maior índice de atividade da enzima $\Delta^{9}$ dessaturase (18) nos animais Nelore. Segundo Malau-Aduli et al. (1997), esta enzima atua inserindo uma dupla ligação na posição 9 da cadeia carbônica do ácido esteárico, convertendo-o em ácido oléico (C18:1 c9).

Tabela 2. Ácidos graxos saturados da gordura de cobertura do contrafilé de tourinhos Nelore e Canchim alimentados com cana de açúcar e dois níveis de concentrado.

\begin{tabular}{|c|c|c|c|c|c|c|c|}
\hline \multirow[b]{2}{*}{ Variável } & \multicolumn{2}{|c|}{ Grupo genético } & \multirow[b]{2}{*}{$\mathrm{P}^{1}$} & \multicolumn{2}{|c|}{$\begin{array}{l}\text { Nível de } \\
\text { concentrado }\end{array}$} & \multirow[b]{2}{*}{$\mathrm{P}$} & \multirow[b]{2}{*}{$\mathrm{CV} \%$} \\
\hline & Nelore & Canchim & & 40 & 60 & & \\
\hline $\begin{array}{l}14: 0 \\
\text { Miristico }\end{array}$ & 5,63 & 4,57 & 0,03 & 5,10 & 5,14 & 0,33 & 25,48 \\
\hline $\begin{array}{l}\text { 15:0 } \\
\text { Pentadecanóico }\end{array}$ & 0,66 & 0,63 & 0,41 & 0,59 & 0,69 & 0,03 & 17,22 \\
\hline $\begin{array}{l}\text { 16:0 } \\
\text { Palmítico }\end{array}$ & 25,48 & 25,14 & 0,73 & 25,33 & 25,30 & 0,93 & 10,48 \\
\hline $\begin{array}{l}\text { 17:0 } \\
\text { Heptadecanóico }\end{array}$ & 0,83 & 0,88 & 0,16 & 0,81 & 0,91 & 0,03 & 10,31 \\
\hline $\begin{array}{l}\text { 18:0 } \\
\text { Esteárico }\end{array}$ & 13,47 & 17,07 & 0,01 & 14,84 & 15,60 & 0,43 & 16,90 \\
\hline $\begin{array}{l}\text { 14:0+16:0 } \\
\text { Mirístico+Palmítico }\end{array}$ & 31,11 & 29,71 & 0,33 & 30,43 & 30,44 & 0,99 & 12,48 \\
\hline
\end{tabular}

${ }^{1} \mathrm{P}$ - Probabilidade; CV - coeficiente de variação.

Fonte: Elaboração dos autores.

Com relação às dietas, não foi verificado efeito nos ácidos mirístico, palmítico e esteárico, porém Oliveira et al. (2012) avaliaram o perfil de ácidos graxos do contrafilé de animais Nelore terminados com dietas contendo diferentes fontes de óleos polinsaturados e não observaram diferenças na concentração de ácido mirístico. Por outro lado, verificou-se que as dietas contendo fontes de óleo de soja, proporcionaram maior deposição de ácido esteárico na carne dos animais. O resultado pode estar relacionado à maior quantidade dos ácidos oléico e linoléico que são precursores, via biohidrogenação ruminal, do ácido esteárico. Ainda referente às dietas, o nível de $60 \%$ de concentrado proporcionou maiores concentrações dos ácidos pentadecanóico (C15:0) e heptadecanóico (C17:0). Provavelmente, o processo de fermentação ruminal desta dieta favoreceu a maior síntese de ácido propiônico
(C3:0) e, conforme descrito por Mansbridge e Blake (1997), este ácido graxo volátil é o precursor dos ácidos C15:0 e C17:0, provenientes da síntese de novo pelas bactérias ruminais. Posteriormente estes ácidos graxos de cadeia ímpar são incorporados nos lipídios microbianos podendo representar de 10 a $15 \%$ do total que chega ao intestino delgado. Estudos recentes têm mostrado que os ácidos graxos de cadeia ímpar e ramificada têm atividade anti-cancerígena e, segundo Vlaeminck et al. (2006), o C15:0, extraído de um produto de soja fermentado inibiu eficientemente o crescimento de células cancerosas, em experimentos in vitro e in vivo. O efeito destes ácidos graxos nas células foi comparável ao do ácido linoléico conjugado (CLA), porém este último, recebeu atenção muito maior como um potencial agente anti-carcinogênico. 
Ainda, na Tabela 2, é possível observar que os grupos genéticos e as dietas avaliadas não proporcionaram efeitos na somatória dos ácidos mirístico (C14:0) e palmítico (C16:0) da gordura de cobertura do contrafilé. Da mesma forma, Fernandes et al. (2009b), não observaram efeito dos grupos genéticos Nelore e Canchim e dos níveis de concentrado de 40 e $60 \%$ na somatória de C14:0 e C16:0 na gordura intramuscular do contrafilé. Fernandes et al. (2009a) ao avaliarem o perfil de ácidos graxos da gordura intramuscular de tourinhos, novilhos e novilhas da raça Canchim também não observaram diferenças para esta característica. Os resultados relatados podem estar associados à pouca idade dos animais utilizados nos diferentes trabalhos, pois em animais jovens não há predominância de deposição de gordura e, de acordo com Marmer, Maxwell e Williams (1984) e Engle et al. (2000), quanto maior a taxa de deposição e a quantidade de gordura corporal, maior a relação entre ácidos graxos saturados e insaturados. Os ácidos graxos C14:0 e C16:0 são considerados hipercolesterolêmicos pois diminuem a atividade dos receptores hepáticos do colesterol reduzindo a sua remoção e metabolização (BESSA, 1999).

Os resultados referentes aos ácidos graxos insaturados são apresentados na Tabela 3. Não foi observado efeito das dietas nos teores dos ácidos graxos insaturados avaliados. É possível observar que a gordura de cobertura do contrafilé dos animais Nelore apresentou maiores teores dos ácidos miristoléico (C14:1 c9) e CLA (C18:2 c9, t11). Da mesma forma, nesse grupo foram identificados maiores índices de atividade das enzimas $\Delta^{9}$ dessaturase $\mathrm{C} 16$ e $\Delta^{9}$ dessaturase $\mathrm{C} 18$. Fernandes et al. (2009b) relataram maiores concentrações dos ácidos graxos monoinsaturados com 14, 16 e 18 carbonos na carne dos animais Nelore, sendo esse resultado, provavelmente, associado com a maior atividade da enzima $\Delta^{9}$ dessaturase e, conforme relatado por Malau-Aduli et al. (1997), essa enzima atua no epitélio intestinal e principalmente no tecido adiposo, sendo sua atividade influenciada pela raça, idade e grau de maturidade fisiológica dos animais. O CLA é produzido pela dessaturação do ácido trans vacênico (C18:1 t11), um produto intermediário do processo de biohidrogenação ruminal do ácido linoléico (C18:2 c9, c12).

Tabela 3. Ácidos graxos insaturados e índice de atividade da $\Delta^{9}$ dessaturase da gordura de cobertura do contrafilé de tourinhos Nelore e Canchim alimentados com cana de açúcar e dois níveis de concentrado.

\begin{tabular}{|c|c|c|c|c|c|c|c|}
\hline \multirow[b]{2}{*}{ Variável } & \multicolumn{2}{|c|}{ Grupo genético } & \multirow[b]{2}{*}{$\mathrm{P}^{1}$} & \multicolumn{2}{|c|}{ Nível de concentrado } & \multirow[b]{2}{*}{$\mathrm{P}$} & \multirow[b]{2}{*}{$\mathrm{CV} \%$} \\
\hline & Nelore & Canchim & & 40 & 60 & & \\
\hline $\begin{array}{l}\text { 14:1 c9 } \\
\text { Miristoléico }\end{array}$ & 1,77 & 1,04 & 0,01 & 1,56 & 1,27 & 0,29 & 51,35 \\
\hline $\begin{array}{l}\text { 16:1 c9 } \\
\text { Palmitoléico }\end{array}$ & 3,85 & 3,33 & 0,08 & 3,80 & 3,39 & 0,15 & 21,06 \\
\hline $\begin{array}{l}\text { 18:1 c9 } \\
\text { Oléico }\end{array}$ & 37,28 & 36,41 & 0,54 & 36,77 & 36,95 & 0,90 & 10,43 \\
\hline $\begin{array}{l}18: 2 \text { c9,c12 } \\
\text { Linoléico }\end{array}$ & 1,44 & 2,40 & 0,01 & 2,02 & 1,80 & 0,27 & 31,28 \\
\hline $\begin{array}{l}18: 2 \mathrm{c} 9, \mathrm{t} 11 \\
\text { CLA }\end{array}$ & 0,86 & 0,59 & 0,03 & 0,80 & 0,75 & 0,48 & 25,26 \\
\hline$\Delta^{9}$ dessaturase $(16)^{2}$ & 13,12 & 11,69 & 0,02 & 13,04 & 11,81 & 0,54 & 13,17 \\
\hline$\Delta^{9}$ dessaturase $(18)^{3}$ & 73,45 & 68,08 & $<0,01$ & 71,24 & 70,31 & 0,64 & 11,69 \\
\hline
\end{tabular}

${ }^{1} \mathrm{P}$ - Probabilidade; CV - coeficiente de variação.

${ }^{2}$ Índice de atividade da enzima $\Delta^{9}$ dessaturase $\mathrm{C} 16=100(16: 1 / 16: 0+16: 1)$.

${ }^{3}$ Índice de atividade da enzima $\Delta^{9}$ dessaturase C18 $=100(18: 1 / 18: 0+18: 1)$.

Fonte: Elaboração dos autores. 
$\mathrm{Na}$ gordura dos animais Canchim, por outro lado, foi observado maior teor do ácido linoléico (C18:2 c9, c12). Resultados semelhantes foram relatados por Fernandes et al. (2009ab), que observaram maiores teores de ácido linoléico na carne do contrafilé de animais Canchim, porém, os valores observados foram superiores aos deste estudo. O ácido linoléico não é sintetizado pelo organismo do animal, desta forma é considerado um ácido graxo essencial. Provavelmente o resultado observado é reflexo da menor quantidade de gordura corporal, pois proporcionalmente, em animais com maior quantidade de gordura observase maiores percentuais de ácidos graxos saturados e seus respectivos monoinsaturados.

Os resultados referentes aos principais grupos de ácidos graxos e suas relações são apresentados na Tabela 4. Observa-se que a gordura de cobertura dos tourinhos Nelore apresentou maiores concentrações de AGPI (ácidos graxos polinsaturados), e também maior relação AGPI:AGS (ácidos graxos polinsaturados:ácidos graxos saturados). Estes resultados refletiram a maior concentração do ácido linoléico conjugado na gordura de cobertura deste grupo genético. A relação AGPI:AGS foi inferior à preconizada pelo Departamento de Saúde do Reino Unido, que recomenda um valor aproximado de 0,4 para caracterizar dessa forma, um alimento mais saudável (WOOD et al., 2003). No trabalho de Fernandes et al. (2009b), observou-se que a relação AGPI:AGS na carne de animais Nelore e Canchim foi superior ao obtido no presente estudo, sendo o valor médio de 0,16. Esse resultado, provavelmente está associado à maior concentração de ácidos graxos polinsaturados nos fosfolipídeos de membrana das fibras musculares (WOOD et al., 2003).

Tabela 4. Ácidos graxos saturados (AGS), insaturados (AGI) monoinsaturados (AGMI), poliinsaturados (AGPI) e relações entre insaturados:saturados (AGI:AGS), monoinsaturados:saturados (AGMI:AGS) e poliinsaturados:saturados (AGPI:AGS) na gordura de cobertura do contrafilé de tourinhos Nelore e Canchim alimentados com cana de açúcar e dois níveis de concentrado.

\begin{tabular}{|c|c|c|c|c|c|c|c|}
\hline \multirow[b]{2}{*}{ Variável } & \multicolumn{2}{|c|}{ Grupo genético } & \multirow[b]{2}{*}{$\mathrm{P}^{1}$} & \multicolumn{2}{|c|}{ Nível de concentrado } & \multirow[b]{2}{*}{$\mathrm{P}$} & \multirow[b]{2}{*}{$\mathrm{CV} \%$} \\
\hline & Nelore & Canchim & & 40 & 60 & & \\
\hline AGS & 46,03 & 48,36 & 0,07 & 46,81 & 47,53 & 0,57 & 7,18 \\
\hline AGMI & 42,91 & 40,79 & 0,09 & 42,14 & 41,61 & 0,67 & 7,87 \\
\hline AGPI & 2,30 & 3,09 & 0,01 & 2,83 & 2,53 & 0,23 & 24,94 \\
\hline AGI:AGF & 0,99 & 0,91 & 0,17 & 0,97 & 0,93 & 0,52 & 14,77 \\
\hline AGMI:AGS & 0,94 & 0,85 & 0,09 & 0,91 & 0,88 & 0,56 & 14,72 \\
\hline AGPI:AGS & 0,07 & 0,05 & 0,01 & 0,06 & 0,05 & 0,25 & 28,66 \\
\hline
\end{tabular}

${ }^{1} \mathrm{P}$ - Probabilidade; CV - coeficiente de variação

Fonte: Elaboração dos autores.

Huerta-Leidenz et al. (1993) avaliaram as quantidades e as relações entre os ácidos graxos da gordura subcutânea de vacas Brahman e Hereford, mantidas em pastagens. Os pesquisadores encontraram maiores teores de AGS para as vacas Hereford e maiores quantidades de AGI, AGMI e AGPI para as Brahman. Os resultados do presente estudo corroboram os encontrados por aqueles autores para AGPI, pois, animais zebuínos possuem carne com maiores quantidades destes ácidos graxos que animais com genótipo europeu. Quando avaliada as relações entre os ácidos graxos, observaram que as vacas Brahman apresentaram melhores relações, sendo que, a relação entre AGPI:AGS foi idêntica ao do presente experimento, tanto para animais Nelore, quanto para Canchim.

No presente trabalho, os diferentes níveis de concentrado não proporcionaram diferenças nos 
principais grupos de ácidos graxos e suas relações, porém, French et al. (2000) observaram que, com a diminuição da proporção de concentrado na dieta e aumento da participação de forragem, houve uma diminuição linear dos AGS. Os pesquisadores encontraram maiores concentrações de AGPI para animais mantidos em pastagem e aumento na relação AGPI:AGS com a diminuição da ingestão de concentrados, em dietas com forragem fresca. Esses resultados foram atribuídos à maior ingestão de ácidos graxos insaturados provenientes da forragem. Segundo Bessa (1999), a classificação e agrupamento de ácidos graxos pelo seu grau de saturação (saturados; monoinsaturados e poliinsaturados) mostra-se defasada em relação aos atuais conceitos relacionados à funcionalidade individual de cada ácido graxo, e assim, penaliza as gorduras dos ruminantes, que constituem uma parte importante dos alimentos ingeridos.

Muitos consumidores não ingerem a gordura de cobertura da carne por acreditarem que esta porção do alimento pode causar elevação do colesterol e aumentar as chances do desenvolvimento de doenças cardiovasculares. Os resultados do presente trabalho indicam que o consumo de pequenas porções desta gordura pode incrementar a ingestão de ácido linoléico conjugado e outros ácidos graxos reconhecidos por suas propriedades nutracêuticas.

\section{Conclusões}

A gordura de cobertura do contrafilé dos animais Canchim e Nelore apresenta quantidades significativas de ácidos graxos benéficos à saúde humana.

Teores de 40 e $60 \%$ de concentrado não alteram a composição em ácidos graxos de tourinhos Nelore e Canchim terminados em confinamento.

\section{Referências}

BESSA, R. J. B. Revalorização nutricional das gorduras dos ruminantes. In: SYMPOSIUM EUROPEO ALIMENTACIÓN EM EL SIGLO, 21., Badajoz, 1999. Anais... Badajoz: Colegio Oficial de Veterinarios de Badajoz, 1999. p. 283-313.

BIESALSKI, H. K. Meat as a component of a healthy diet - are there any risks or benefits if meat is avoided in the diet? Meat Science, Amsterdam, v. 70, n. 2, p. 509524, 2005.

BLIGH, E. G.; DYER, W. J. A rapid method of total lipid extraction and purification. Canadian Journal of Biochemistry and Physiology, Ontario, v. 37, n. 8, p. 911917, 1959.

ENGLE, T. E.; SPEARS, J. W.; ARMSTRONG, T. A.; WRIGHT, C. L.; ODLE, J. Effects of dietary cooper source and concentration on carcass characteristics and lipid and cholesterol metabolism in growing steers. Journal of Animal Science, Champaign, v. 78, n. 3, p. 1053-1059, 2000.

FERNANDES, A. R. M.; SAMPAIO, A. A. M.; HENRIQUE, W.; OLIVEIRA, E. A.; OLIVEIRA, R. V.; LEONEL, F. R. Composição em ácidos graxos e qualidade da carne de tourinhos Nelore e Canchim alimentados com dietas à base de cana-de-açúcar e dois níveis de concentrado. Revista Brasileira de Zootecnia, Viçosa, v. 38, n. 2, p. 328-337, 2009b.

FERNANDES, A. R. M.; SAMPAIO, A. A. M.; HENRIQUE, W.; TULLIO, R. R.; OLIVEIRA, E. A.; SILVA, T. M. Composição química e perfil de ácidos graxos da carne de bovinos de diferentes condições sexuais recebendo silagem de milho e concentrado ou cana-de-açúcar e concentrado contendo grãos de girassol. Revista Brasileira de Zootecnia, Viçosa, v. 38, n. 4, p. 705-712, 2009a.

FOX, D. G.; SNIFFEN, C. J.; O'CONNOR, J. D.; RUSSELL, J. B.; VAN SOEST, P. J. A net carbohydrate and protein system for evaluating cattle diets. III. Cattle requirements and diets adequacy. Journal of Animal Science, Champaign, v. 70, n. 11, p. 3578-3596, 1992.

FRENCH, P.; STANTON, C.; LAWLESS, F.; O'RIORDAN, J. F.; MONAHAN, F. J.; CAFFREY, P. J.; MOLONEY, A. P. Fatty acid composition, including conjugated linoleic acid, of intramuscular fat from steers offered grazed grass, grass silage or concentrate based diets. Journal of Animal Science, Champaign, v. 78, $\mathrm{n}$. 11, p. 2849-2855, 2000. 
HUERTA-LEIDENZ, N. O.; CROSS, H. R.; SAVELL, J. W.; KUNT, D. K.; BAKER, J. F.; PILTON, L. S.; SMITH, S. B. Comparison of the fatty acid composition of subcutaneous adipose tissue from mature Brahman and Hereford cows. Journal of Animal Science, Champaign, v. 71, n. 3, p. 625-630, 1993.

MALAU-ADULI,A.E. O.; SIEBERT, B.D.;BOTTEMA, C. D. K.; PITCHFORD, W. S. A comparison of the fatty acid composition of tryacilglycerols in adipose tissue from Limousin and Jersey cattle. Australian Journal of Agriculture Research, Collingwood, v. 48, n. 5, p. 715722, 1997.

MANSBRIDGE, R .J.; BLAKE, J. S. Nutritional factors affecting the fatty acids composition of bovine milk. British Journal of Nutrition, Cambridge, v. 78, p. 37-47, 1997. Supplement 1.

MARMER, W. N.; MAXWELL, R.; WILLIAMS, J. E. Effects of dietary regimen and tissue site on bovine fatty acid profiles. Journal of Animal Science, Champaign, v. 59, n. 1, p. 109-121, 1984.

MIR, P. S.; IVAN, M.; HE, M. L.; PINK, B.; OKINE, E.; GOONEWARDENE, L.; MCALLISTER, T. A.; WESELOKE, R.; MIR, Z. Dietary manipulation to increase conjugated linoleic acids and other desirable fatty acids in beef: A review. Canadian Journal of Animal Science, Ottawa, v. 83, n. 4, p. 673-685, 2003.

OLIVEIRA, E. A.; SAMPAIO, A. A. M.; FERNANDES, A. R. M.; HENRIQUE, W.; OLIVEIRA, R. V.; RIBEIRO, G. M. Desempenho e características de carcaça de tourinhos Nelore e Canchim terminados em confinamento recebendo dietas com cana-de-açúcar e dois níveis de concentrado. Revista Brasileira de Zootecnia, Viçosa, v. 38, n. 12, p. 2465-2472, 2009.
OLIVEIRA, E. A.; SAMPAIO, A. A. M.; HENRIQUE, W.; PIVARO, T. M.; ROSA, B. L.; FERNANDES, A. R. M.; ANDRADE, A. T. Quality traits and lipid composition of meat from Nellore young bulls fed with different oils either protected or unprotected from rumen degradation. Meat Science, Amsterdam, v. 990, n. 1, p. 28-35, 2012.

SAMPAIO, I. B. M. Estatística aplicada à experimentação animal. 2. ed. Belo Horizonte: FEPMVZ, 2002. 265 p.

TAUBES, G. The soft science of dietary fat. Science, Washington, v. 291, n. 5513, p. 2536-2541, 2001.

VACANTI, L. J.; SANTOS, S. C. M.; FUJITA, A. M.; LIMA, D. S.; LOPES, A. F.; VETORAZI, R.; SELLERO, A.; SCARIN, N. R. A baixa taxa de obtenção da meta do LDL-colesterol numa população de baixa renda. Arquivos Brasileiros Cardiologia, Rio de Janeiro, v. 85, n. 3, p. 162-165, 2005.

VLAEMINCK, B.; FIEVEZ, V.; CABRITA, A. R. J.; FONSECA, A. J. M.; DEWHURST, R. J. Factors affecting odd- and branched-chain fatty acids in milk: A review. Animal Feed Science and Technology, Amsterdam, v. 131, n. 2, p. 389-417, 2006.

WOOD, J. D.; RICHARDSON, R. J.; NUTE, G. R.; FISHER, A. V.; CAMPO, M. M.; KASAPIDOU, E.; SHEARD, P. R.; ENSER, M. Effects of fatty acids on meat quality: a review. Meat Science, Amsterdam, v. 66, n. 1, p. 21-32, 2003. 
